\title{
Transporting devices for grain with new types of working units from polymeric materials
}

\author{
Andrey Dorochov ${ }^{1}$, Maksim Moskovskiy ${ }^{1, *}$, and Mikhail Chaava ${ }^{2}$ \\ ${ }^{1}$ Federal Scientific Agroengineering Center VIM, 1-st Institutsky proezd, 5, Moscow, 109428, Russia. \\ ${ }^{2}$ Don State Technical University, Gagarin Square, 1, Rostov-on-Don, 344000, Russia.
}

\begin{abstract}
The existing standard technologies for obtaining seeds of various reproductions in farms have a wide variation in the initial harvesting parameters, mechanization and technological modes of operation, which affects the final quality indices of seed material and its cost price. Modernization of the working parts of machines and units that provide the technology of loading and reloading operations will improve the quality of grain at this stage of harvesting. The installation of a new type of transporting device in a typical grain-handling machine loader allows to reduce the crushing and damage of grain by more than $20 \%$.
\end{abstract}

\section{Introduction}

In the operations associated with post-harvest processing of seeds, loading and unloading, transporting devices of various types are repeatedly used. The auger type and conveyor type of devices are often used in technological processes of production and processing in the operation of obtaining grain. The influence of these devices on the seeds material with variation of the working bodies and changes in the quality of grain seeds during transportation has not been thoroughly studied. Particularly interesting is the influence of these types of devices on the mains criteria's for the quality of seeds, such as damage, micro damage, growth force, field germination.

These criteria's are fundamental in producing high yields. The possibility of changing these criteria's gives an impact to improving the efficiency of transporting devices due to a variation in the design and kinematic parameters.

The aim of the studies is a comparative analysis of the influence of different types of transport system on the quality index of seeds: germination, germination of the investigated cereal crops and a comprehensive indicator of the damage of these materials, as well as comparative tests of the modernizing transport device with typical analogs in the field, harvesting grain crops.

\section{Materials and methods}

The program of experimental studies included the identification of regularities in the change

\footnotetext{
* Corresponding author: maxmoskovsky74@yandex.ru
} 
in the quality indices of grain seeds during their transportation and the determination of the degree of wear resistance of auger working bodies which made of polymer materials. A laboratory installation has been created for this purpose (Figure 1).

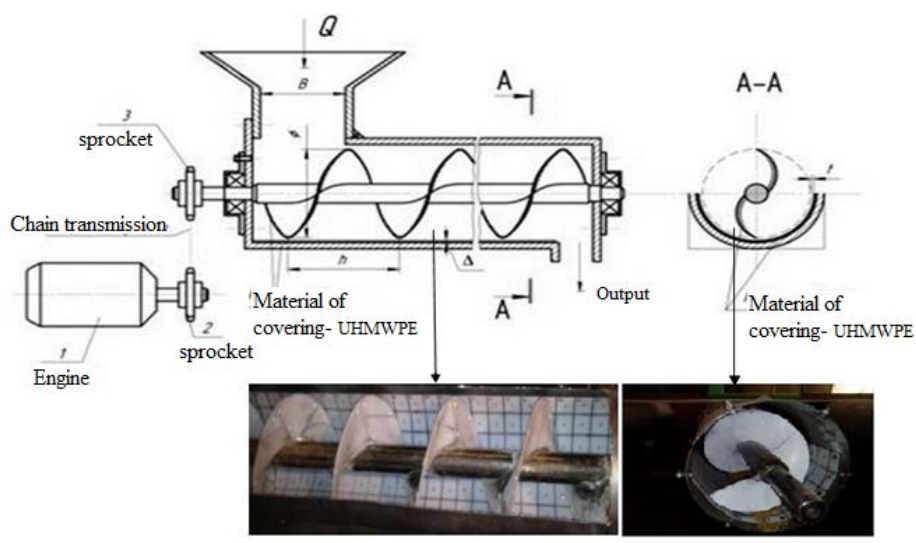

Fig. 1. Laboratory installation for determining the degree of impact on grain material by the modernized working bodies of the transporting auger.

The following studies were carried out by using laboratory installation:

- determination of the effect of constructive, design parameters and productivity of auger conveyors on the quality indicators of grain seeds;

- determination of wear resistance of auger bodies which made of polymeric materials;

- determination of specific energy intensity of transportation of grain materials;

- determination of technical and economic indicators of the functioning of the combined auger conveyor.

The laboratory installation consists of a rigid frame on which are mounted the auger blocks, the bunker, the drive of the augers consisting of chain transmission and electrical equipment.

Augers are situated in pairs and horizontally and driven into rotation by electric motor through a chain drive. The speed of rotation is regulated by transformer in the range $0-800$ $\min ^{-1}$.

A laboratory autotransformer with a voltmeter is connected to the installation, by means of which the frequency of rotation of the working organs changes.

The auger covering is replaceable and it is made from different types of material: metal, polymer, polymer based on UHMWPE.

The working coils of the combined auger are made from UHMWPE material and installed by attaching the lining to the metal cavity. There is a cutout for viewing windows and observing the movement of the stream. (Figure 2).

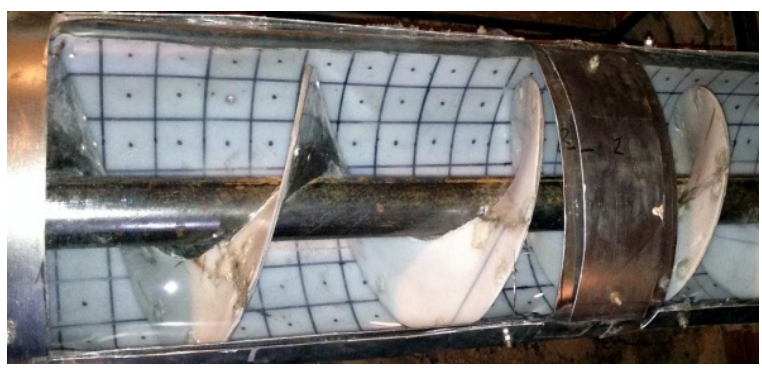

Fig. 2. Viewing window of the experimental combined auger. 
The studies were carried out using the theory of multifactor planning with an assessment of the parameters of the transported grain material.

The main parameters were determined after carrying out theoretical studies and a series of preliminary experiments:

1. Feeding of grain material $-\mathrm{X}_{1}$;

2. Coefficients of friction (characterizing the material used for the casing and the working member of the auger) $-\mathrm{X}_{2}$;

3 . Frequency of rotation of the auger- $\mathrm{X}_{3}$;

The studies were carried out according to the plan of a fractional factor experiment with by varying the investigated factors at three levels (Table 1).

Table 1. Factors and levels of variation.

\begin{tabular}{|c|c|c|c|c|}
\hline \multicolumn{2}{|c|}{ Factors designation } & Factors & Levels & Definition \\
\hline Codes & Natural & Feeding of grain material & $-1 \ldots 0 \ldots 1$ & $50 \ldots 100 \ldots 150$ \\
\hline $\mathrm{X}_{1}$ & $\mathrm{Q}$ & $\begin{array}{c}\text { Materials (metal, polimer, } \\
\text { UHMWPE) }\end{array}$ & $-1 \ldots 0 \ldots 1$ & $20 \ldots 25 \ldots 30$ \\
\hline $\mathrm{X}_{2}$ & $\varepsilon$ & $\begin{array}{c}\text { Frequency of rotation of } \\
\text { the working body, } \text { min }^{-1}\end{array}$ & $-1 \ldots 0 \ldots 1$ & $250 \ldots 500 \ldots 750$ \\
\hline $\mathrm{X}_{3}$ & $\mathrm{n}$ &
\end{tabular}

We identified necessary number of experiments -27 experiments, proceeding from 3 factors and 3 levels of their variation. A number of literary sources indicate that such a number of experiments is redundant and it is possible to reduce their number. This can be achieved using fractional replicas or fractional factor experiments.

A comparative field analysis was carried out using standard and combined augers based on polymeric materials.

The following types of bunker machines with a variation of the main working body are considered:

1. The machine "Bunker reloader" / type of working organ - auger; auger made of metal.

2. The machine "Bunker reloader" / Type of working organ - auger; auger plastic from polymer material UHMWPE.

The system was calibrated at the input so that the mass flow of cereals was corrected. The settings were determined for the indicators of 50, 100, 150 tons per hour. The sampling was carried out when the combine was unloaded from the hopper and at the exit from the hopper bunker.

\section{Results and discussions}

The work of these types of working bodies was evaluated according to various quality indicators: wear resistance, reliability, the influence of various working surfaces on grain trauma, analysis of kinematic regimes for transported grain material.
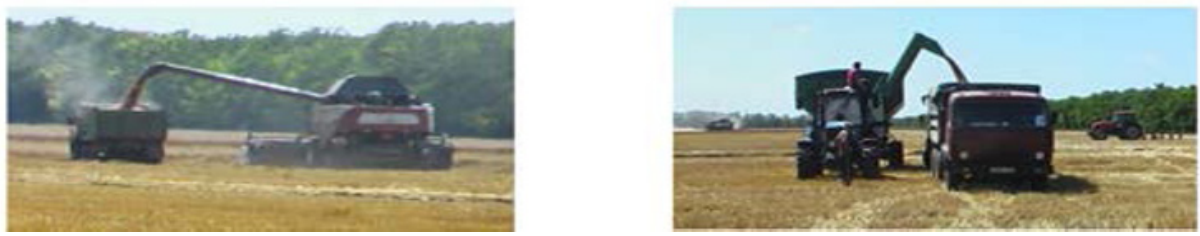

Fig. 3. Unloading and reloading grain in the field. 

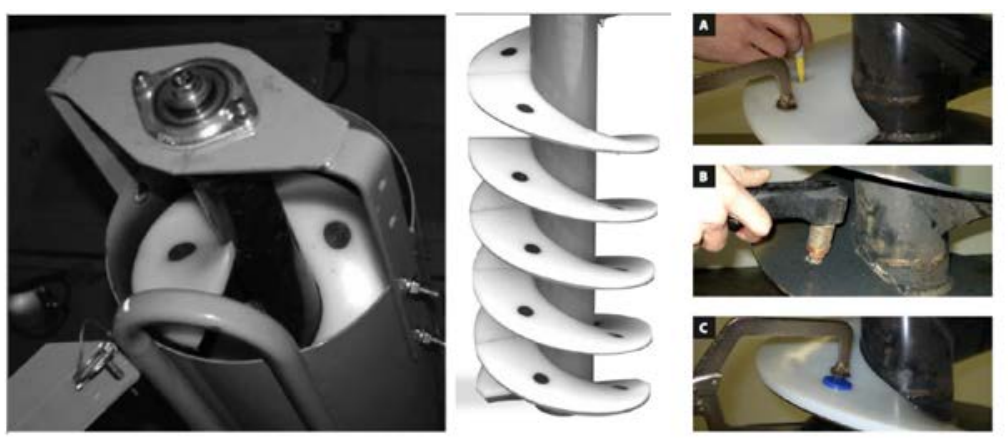

Fig. 4. Mounted polymeric covering on auger

The first purpose of the experiment is analyzing the wear resistance of workers surfaces. The degree of abrasion of the control points of the expanded auger arc $\left(\mathrm{t}_{1}\right.$ - control line 120 hours, $\mathrm{t}_{2}$-control line 240 hours). (Figure 5).
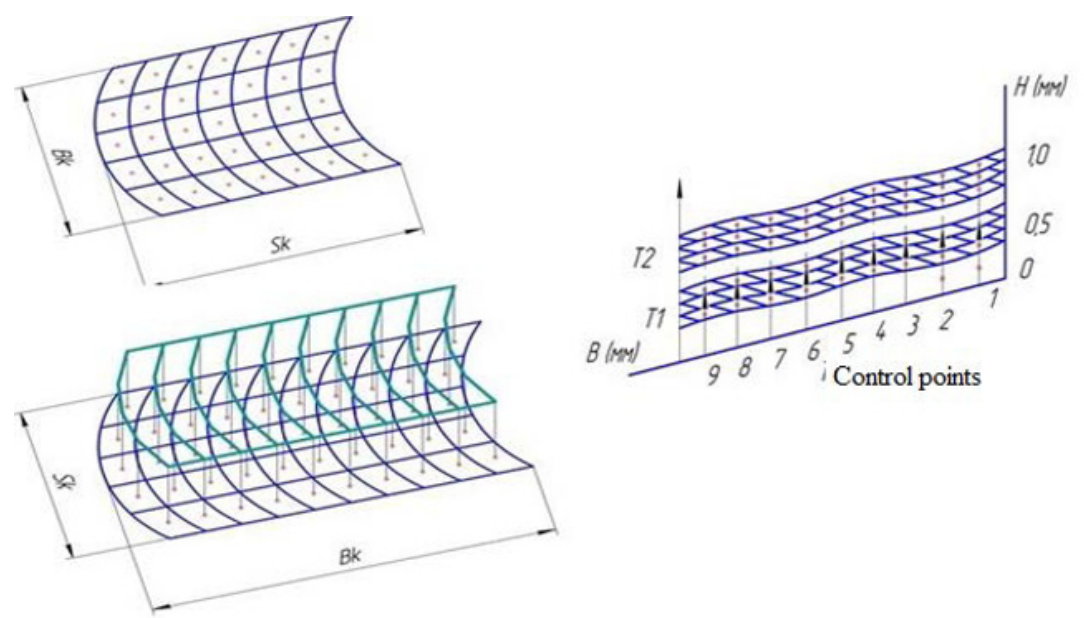

Fig. 5. Control points of abrasion of covering.

A comparative analysis of the abrasion of control points in the $\mathrm{B} \times \mathrm{S}$ section, the expanded circumference of the covering of the UHMWPE material (plane -1, (Figure 6) and the casing made of metal (plane 2, (Figure 6)).

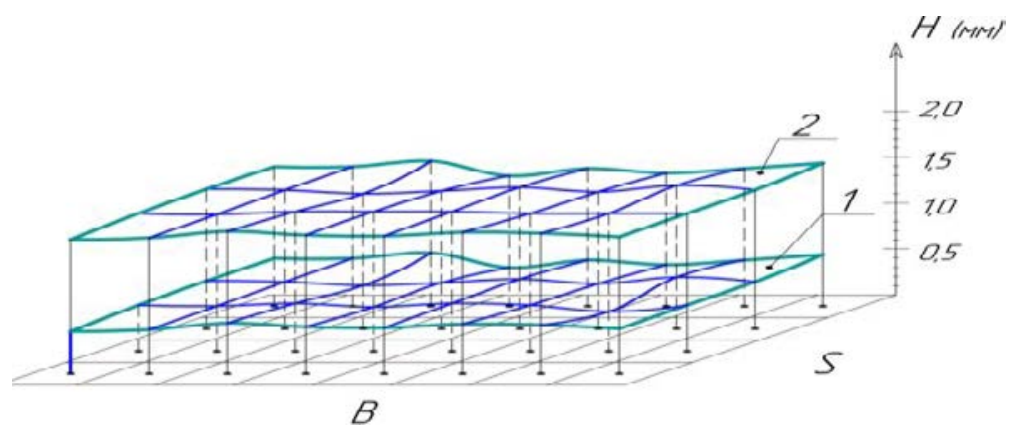

Fig. 6. Comparative analysis of abrasion planes with different casing materials: 1 - the covering made of polymer material UHMWPE; 2- covering made of metal. 
The obtained data indicate of decreasing in abrasion of the working surfaces of augertype conveying devices at $72.5 \%$. Subsequent laboratory studies were conducted to study the effect of working body, covering of transport devices, on the quality indicators of grain material. As a control sample, grain material that was not transportable (grain output from the combine harvester) was acting. When comparing all combinations of types of transport systems compared to the control group, it was found that they reduce germination by $7.4 \%$ for wheat and $8.2 \%$ for barley culture.

It is assumed that during using auger transporting working bodies, it is possible to reduce the damage of the grain, by reducing its contact with the edges and gaps between the auger and the covering, also with a "soft" grain outlet and contact with the baffles of the discharge hole. For comparison, modified augers made by combining various polymer materials were included. A definite dependence of the increase in microcracks (Figure 7) as well as the influence of variable factors in the transport of cereals in screw conveyors.

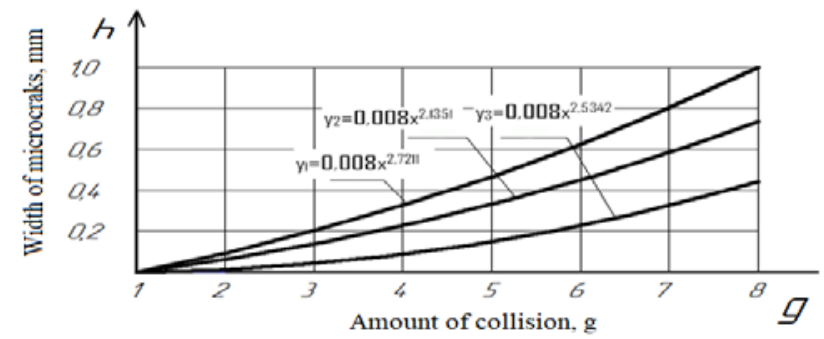

Fig. 7. Dependence of the increase in the width of microcracks on the amount of collisions of grain on the working surface.

Table 2. Influence of variable factors in the transportation of cereals in the department of auger working organs on indicators of seed injuries.

\begin{tabular}{|c|c|c|c|}
\hline \multicolumn{2}{|c|}{$\begin{array}{l}\text { Ratio of the percentage of damage seeds to the zones of the } \\
\text { auger conveyor, depending on various factors }\end{array}$} & \multicolumn{2}{|c|}{ : } \\
\hline $\begin{array}{l}\text { Factors influence on the grain } \\
\text { damage }\end{array}$ & Zone of input, $\%$ & Zone of transporting, $\%$ & Zone of output, $\%$ \\
\hline $\begin{array}{l}\text { Types of working body: } \\
\text { - Auger from metal } \\
\text { - auger brush-shaped } \\
\text { - auger from polymer material } \\
\text { UHMWPE }\end{array}$ & $\begin{array}{l}10 \\
10 \\
-\end{array}$ & $\begin{array}{l}80 \\
80 \\
50\end{array}$ & $\begin{array}{l}10 \\
10 \\
-\end{array}$ \\
\hline Auger rotation speed & 5 & 90 & 5 \\
\hline $\begin{aligned} \text { Researching crop: } \\
-\quad \text { Wheat } \\
-\quad \text { - barley }\end{aligned}$ & $\begin{array}{l}15 \\
10\end{array}$ & $\begin{array}{l}70 \\
80\end{array}$ & $\begin{array}{l}15 \\
10\end{array}$ \\
\hline Feeding on input (Material layer) & 25 & 60 & 15 \\
\hline $\begin{array}{l}\text { Constructive parameters of reflectors } \\
\text { on input and output }\end{array}$ & 25 & - & 25 \\
\hline
\end{tabular}




\section{Conclusions}

The generalized conclusion shows that the use of auger combined working elements made of polymeric materials at high speed operation $n=800 \mathrm{~min}^{-1}$ provides maximum productivity and allows to reduce the process of grain damage by more than $20 \%$ compared to typical working bodies on a metal base and thereby increase germination capacity of more than $7 \%$ percent for the studied crops. The difference in damage at the maximum productivity of the grain being loaded is 150 tons/hour, the screw on a plastic base, compared with the metal, for the studied crops, was from 6.2 to $12.1 \%$. The maximum value of the germination index of seeds with minimal trauma was ensured by feeding a 100 tons/hour auger on a plastic base.

\section{Reference}

1. Paulsen M. R., Nave W. R. Corn damage from conventional and rotary combines, Transactions of the ASABE, 23(5), pp 1100-1116. (1980)

2. Wang Y. J., Chung D. S., Spillman C. K., Eckhoff S. R., Rhee C., Converse H. H. Evaluation of laboratory grain cleaning and separating equipment, Transactions of the ASABE, 37(2), pp 507-513. (1994)

3. Moskovsky, M.N., Chumak, I.V., Chaava, M.M., Development of a structural-functional model of a single production process obtaining seed material in farms, ARPN Journal of Engineering and Applied Sciences, 13(6), pp. 6414-6418. (2018)

4. Moskovskiy M.N., Pakhomov V.I., Vesnin V.N., Investigation of the interaction of the components of the harvested grain material on the surface of the working organs of the combine harvester equipped with UHMWPE coating, Izvestiya Samara Scientific Center of the Russian Academy of Sciences, 4 (2), pp. 531-533 (2013) 